\title{
Racial/ethnic differences in the burden of type 2 diabetes over the life course: a focus on the USA and India
}

\author{
Sherita H. Golden ${ }^{1}$ - Chittaranjan Yajnik ${ }^{2}$ - Sanat Phatak ${ }^{2}$ • Robert L. Hanson ${ }^{3}$ - William C. Knowler ${ }^{3}$
}

Received: 23 April 2019 / Accepted: 16 July 2019 / Published online: 27 August 2019

(C) Springer-Verlag GmbH Germany, part of Springer Nature 2019

\begin{abstract}
Type 2 diabetes is a common disease worldwide, but its prevalence varies widely by geographical region and by race/ethnicity. This review summarises differences in the frequencies of type 2 diabetes according to race, ethnicity, socioeconomic position, area of residence and environmental toxins. Type 2 diabetes susceptibility often begins early in life, starting with genetic susceptibility at conception and continuing in later life, via in utero, childhood and adult exposures. Early-life factors may lead to overt type 2 diabetes in childhood or in later life, supporting the concept of developmental origins of health and disease. The causes of the racial/ethnic differences in incidence of type 2 diabetes are not well understood. Specifically, the relative contributions of genetic and environmental factors to such differences are largely unknown. With a few exceptions in isolated populations, there is little evidence that differences in frequencies of known type 2 diabetes susceptibility genetic alleles account for racial/ethnic differences, although the search for genetic susceptibility has not been uniform among the world's racial/ethnic groups. In the USA, race/ethnicity is associated with many other risk factors for type 2 diabetes, including being overweight/ obese, diet and socioeconomic status. Some studies suggest that some of these factors may account for the race/ethnic differences in prevalence of type 2 diabetes, although there is inadequate research in this area. A better understanding of the impact of these factors on type 2 diabetes risk should lead to more effective prevention and treatment of this disease. This has not yet been achieved but should be a goal for future research.
\end{abstract}

Keywords Life course development $\cdot$ Race/ethnicity $\cdot$ Review $\cdot$ Type 2 diabetes mellitus

\begin{abstract}
Abbreviations
GDM Gestational diabetes mellitus

NHIS National Health Interview Survey

SES Socioeconomic status
\end{abstract}

Electronic supplementary material The online version of this article (https://doi.org/10.1007/s00125-019-4968-0) contains a slideset of the figures for download, which is available to authorised users.

William C. Knowler

knowler@nih.gov

1 Department of Medicine, Johns Hopkins University School of Medicine, Baltimore, MD, USA

2 Diabetes Unit, KEM Hospital and Research Center, Pune, Maharashtra, India

3 Phoenix Epidemiology and Clinical Research Branch, National Institute of Diabetes and Digestive and Kidney Diseases, National Institutes of Health, 1550 East Indian School Road, Phoenix, AZ 85014, USA

\section{Introduction}

Type 2 diabetes is a common disease worldwide, but its prevalence varies widely by geographical region and by race/ethnicity. For example, Fig. 1 shows age-specific prevalence of diagnosed diabetes in the USA, according to selfreported race/ethnicity. In older adults ( $\geq 75$ years of age), prevalence ranges from $17.7 \%$ in non-Hispanic white individuals to $45.2 \%$ in American Indians/Alaska Natives [1].

Type 2 diabetes is considered a complex disease, in that many known genetic, environmental and personal behavioural risk factors affect disease susceptibility and few, if any, variables are completely determinative. Other, yet undiscovered, risk factors also likely contribute to this disease. In this article, we review these complex causes and discuss the extent to which they may explain the racial/ethnic differences in type 2 diabetes prevalence. We focus on research from the USA and India, regarding factors influencing the development of type 2 diabetes, rather than those influencing management and consequences of the disease, such as the development of acute 
Fig. 1 Age-specific prevalence of diagnosed diabetes in the USA by race/ethnicity. Data from the NHIS, 2011-2015, reported in [1]. AI/AN, American Indian/ Alaska Native; NHB, nonHispanic black; NHW, nonHispanic white. This figure is available as part of a downloadable slideset

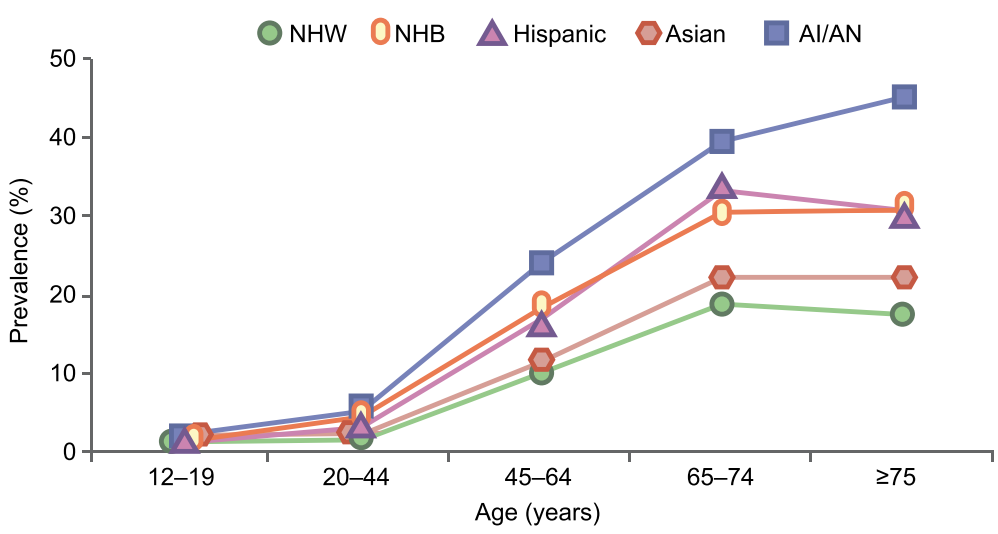

metabolic and chronic vascular complications. Because the incidence of complications is strongly related to duration of diabetes, factors leading to younger age of onset of type 2 diabetes are also associated with greater prevalence of complications over the lifetime, but whether differences in the prevalence or incidence of complications are due to factors other than those leading to type 2 diabetes itself is beyond the scope of this review. While not a meta-analysis or systematic review, this paper includes findings that we consider representative and relevant to $\mathrm{racial} / \mathrm{ethnic}$ differences in type 2 diabetes susceptibility.

Although previously considered primarily a disease only of adults (and formerly called 'adult-onset diabetes'), what is now called type 2 diabetes also occurs in children. Evidence suggests that susceptibility often begins early in life, starting at conception, owing to genetics, and continues in later life via in utero, childhood and adult exposures. Early-life factors may lead to overt type 2 diabetes in childhood or later, confirming the concept of developmental origins of health and disease.

Although race and ethnicity are associated with health and disease incidence [2-4], these terms have not been used consistently in the medical literature. In the USA, 'race' indicates continent or region of ancestral origin and 'ethnicity' (Hispanic or not) indicates cultural identity. Hispanic ethnicity refers to people who identify with a Spanish-speaking culture. Any racial group may also identify as Hispanic or nonHispanic. Thus, in the USA 'non-Hispanic black' refers to people of African descent who do not identify as Hispanic; 'non-Hispanic white' refers to those with ancestry from Europe or the Mediterranean who do not identify as Hispanic; Asian-American refers to individuals of East Asian, South Asian, South East Asian and Pacific Island ancestry; and American Indian/Alaska Native to descendants of the original inhabitants of the Americas $[5,6]$. These categories are based on self-report and include heterogeneous groups. Analogous terms are not used uniformly in other parts of the world. In this review, when studies are discussed that use more specific terms in defining racial/ethnic subgroups, we will use them accordingly.

\section{Genetics and differences in diabetes prevalence}

Given the many genetic differences among racial/ethnic groups and the well-recognised genetic influences on type 2 diabetes, genetic factors probably account, in part, for the differences in diabetes prevalence. However, few studies have quantified the contributions of genetic factors to these racial/ ethnic differences. In Mexican-Americans, a higher proportion of American Indian ancestry, determined by skin reflectance, was associated with higher prevalence of diabetes [7]; similar findings were seen in Pima Indians, with American Indian ancestry determined by self-report [8]. Studies that used 'traditional' genetic markers, such as blood groups, to estimate American Indian heritage also found positive associations with diabetes in Pima and Mexican-American populations [9-11]. With the advent of modern genetic techniques, large numbers of ancestry-informative genetic markers can be typed, resulting in more robust estimates of genetic ancestry. Studies using these techniques in Hispanic populations have also found that a higher level of American Indian ancestry is associated with higher prevalence of diabetes [12-15]. However, American Indian ancestry was also associated with socioeconomic status (SES), and adjustment for SES greatly attenuated the risk associated with genetic admixture. In studies of African-American individuals, a higher proportion of African ancestry was associated with increased prevalence of diabetes and this finding persisted with adjustment for SES [16]. Given the imprecision in assessing environmental sociocultural factors shared within ancestry groups, genetic ancestry associations may be confounded by environmental factors. One might expect comparisons of genetic ancestry estimates within sibships to be robust to such confounding, but such studies require large sample sizes and large numbers of genetic markers to confidently assess the modest differences in genetic admixture among siblings.

Genome-wide association studies have now identified over 200 genetic variants that are reproducibly associated with type 2 diabetes across multiple racial/ethnic groups [17]. Most 
have small effects on diabetes risk, but a few, which are rare in most global populations, have strong effects. A few of these rare variants are considerably more common in certain, relatively isolated populations, and these variants may explain a substantial portion of the excess risk in these isolated populations. Examples include an $H N F 1 A$ variant in Oji-Cree Indians and a TBC1D4 variant in Inuit people $[18,19]$. For multiple 'established' diabetes variants, one approach to assessing the importance of genetic factors in racial/ethnic differences is to compare allele frequencies across these susceptibility variants, for example, by analysis of polygenic risk scores. Several studies have shown that allele frequencies diverge markedly at established type 2 diabetes susceptibility variants across continental ancestry groups, with the greatest genetic risk occurring in African populations, the lowest genetic risks in East Asians and American Indians, and an intermediate risk in Europeans (for example, see Fig. 2) [20-23]. This pattern does not correspond to the epidemiological risk of diabetes, which is highest in American Indians and, thus, these allele frequency differences cannot account for the high prevalence of diabetes in American Indians, though they may partially explain some of the differences between African-Americans and European-Americans [23]. These studies were conducted with relatively small numbers of established variants, and they are limited by incomplete ascertainment of genetic variants influencing diabetes (many likely remain unknown) and by incomplete knowledge of the causal variants underlying the associations (which may differ across race/ethnicities due to different linkage disequilibrium patterns).

\section{Early-life risk factors for type 2 diabetes}

Some evidence of early-life determinants of type 2 diabetes comes from India and is discussed here as a model of diabetes susceptibility in economically deprived societies. With rapid economic growth, India has had an alarming rise in type 2 diabetes prevalence out of proportion to its increase in affluence [24]. The rise has been most pronounced in the states that have suffered financial, geographical or sociopolitical difficulties. This points towards a role for previous deprivation in the evolution of the diabetes epidemic. Traditionally, type 2 diabetes susceptibility is ascribed to a 'thrifty genotype' that evolved over millennia. However, the 'thrifty phenotype' hypothesis [25] suggests a more recent establishment of susceptibility through epigenetic programming due to enhanced survival in the setting of intergenerational undernutrition, especially during the first 1000 days of life (intrauterine and first 2 years). Thus, intergenerational influences seem to operate both genetically and epigenetically.

Adults with type 2 diabetes in the Indian subcontinent differ in phenotype from the 'textbook' description of European individuals [26]. The differences may be explained, at least in part, by early-life exposures. Indian individuals with type 2 diabetes are diagnosed at least a decade earlier and have a lower BMI but higher central obesity at diagnosis [27]. Body fat percentage in Indian populations is higher than that in European individuals at a given BMI [28, 29]; this 'thin-fat' phenotype is associated with higher insulin resistance and diabetic dyslipidaemia. Recent investigations also revealed that Indian people with type 2 diabetes have reduced beta cell function compared with Europeans [30]. This phenotype is clearly not attributable to adult lifestyle factors only; a comparison of newborn Indian and English babies revealed that it originates during intrauterine development [31], supporting the 'thrifty phenotype' hypothesis [25, 32]. This 'thin-fat' and impaired beta cell function phenotype suggests a new explanation for the high susceptibility of Indian individuals to type 2 diabetes since more than a quarter of Indian babies have low birthweight $(<2.5 \mathrm{~kg})$, multigenerational undernutrition with small maternal size is common, and Indian babies are among the smallest in the world. A small and thin Indian newborn (mean weight $2.7 \mathrm{~kg}$ ) has comparable subscapular skinfold thickness to an English baby (mean weight $3.5 \mathrm{~kg}$ ) [32] and higher subcutaneous and visceral fat as assessed by MRI [33]. The cord blood of Indian babies also has higher concentrations of leptin and insulin, but lower concentrations of adiponectin, confirming a high-risk profile for future type 2 diabetes [34]. The contribution of genetics and epigenetics to this phenotype is currently being actively investigated [35, 36].

The Pune Children's study demonstrated that children born small had higher glucose and insulin concentrations during a glucose tolerance test [37]. Babies born small who grew to have high fat mass later in childhood had the highest levels of risk factors for type 2 diabetes and cardiovascular disease (insulin resistance, high adiposity, lipid abnormalities and high blood pressure) [38]. The Delhi cohort expanded these findings in young individuals with glucose intolerance: glucose intolerant individuals were born smaller compared with glucose tolerant participants, grew poorly in the first 2 years of life, and then progressively increased in weight and BMI until adult age. Though not obese by international criteria, individuals who had greater weight gain in relation to their early years were at higher risk of type 2 diabetes [39].

This life course trajectory exemplifies the risk of 'double burden' of malnutrition on lifetime risk for type 2 diabetes, a common situation in the developing populations of the world. The 'dual teratogenesis' construct [40] describes the progressive evolution of risk factors and type 2 diabetes in the intergenerationally undernourished who tend to be 'thin-fat', insulin resistant and beta cell deficient in rural environments, but become obese and glucose intolerant when they live in more urbanised conditions. Urbanisation produces an unmanageable load of overnutrition and physical inactivity on a multigenerationally low capacity system [41, 42]. This is 


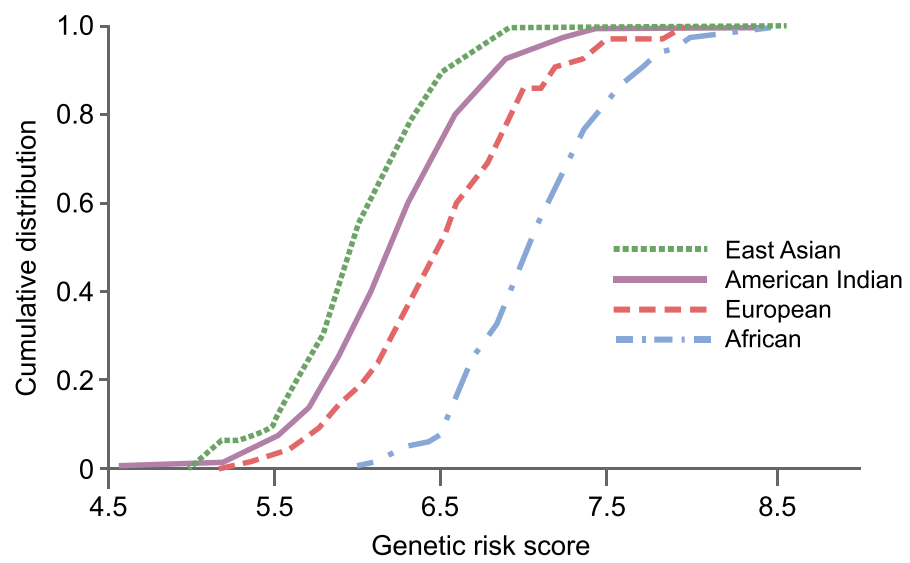

Fig. 2 Cumulative distribution of genetic risk score for type 2 diabetes, calculated by summing the number of risk alleles weighted by the published effect size across 63 established variants, in different racial/ethnic groups. American Indians were Pima Indians who participated in a longitudinal study; the other populations were derived from the International HapMap project and included Han Chinese individuals from Beijing (East Asians), Centre d'Etude du Polymorphisme Humain families from

supported by the finding that urban middle-class Indians were more insulin resistant than urban slum dwellers and individuals living in rural areas [43]. In addition, beta cell responses in South Asian individuals were incommensurate with the degree of insulin resistance, signifying beta cell dysfunction [44] and suggesting that pancreatic development is suboptimal in early life.

Diet probably plays a major role in influencing intergenerational susceptibility to type 2 diabetes. In Indian and other populations in which vegetarianism is common, there is a substantial prevalence of vitamin $\mathrm{B}_{12}$ deficiency. Maternal vitamin $B_{12}$ deficiency and hyperhomocysteinaemia are related to poor fetal growth, and subsequent insulin resistance and adiposity in childhood [45]. High folate status worsens the situation, suggesting that a balance between vitamin $\mathrm{B}_{12}$ and folate is essential. Moreover, Indian diets are associated with macronutrient imbalances; they tend to be high in energy and carbohydrates and have a high glycaemic index [46]. In addition to diet, South Asians, as a group, seem to be less physically active than their European counterparts [47]. All these factors combine to bring about the higher, earlier susceptibility to type 2 diabetes in South Asian populations.

\section{Prevalence and incidence of type 2 diabetes in youth}

There are limited global data on prevalence and incidence of newly diagnosed type 2 diabetes in children and adolescents. Among the earliest reports of type 2 diabetes in children were those from the Pima Indians, where prevalence was based on case finding by glucose tolerance testing [48]. The prevalence of type 2 diabetes in youth has increased over time in the Pima
Utah (Europeans) and Yoruba people from Ibadan Nigeria (Africans). A rightward shift of the curve is suggestive of a higher genetic risk for type 2 diabetes. Adapted from [23], American Diabetes Association (2015). Copyright and all rights reserved. Material from this publication has been used with the permission of American Diabetes Association. This figure is available as part of a downloadable slideset

Indian population; for example, in girls aged 15-19 years, type 2 diabetes prevalence increased from $2.73 \%$ in $1967-1976$ to $5.31 \%$ in 1987-1996, while, in boys, it increased from $2.43 \%$ to $3.78 \%$ over the same time periods [49]. Much less is known about type 2 diabetes in children in other populations because most studies have relied on clinical diagnoses rather than case finding by glucose tolerance testing, unlike the Pima Indian studies. Data on clinically diagnosed type 2 diabetes in different racial/ethnic groups were obtained in the SEARCH for Diabetes in Youth Study [50]. Prevalence of type 2 diabetes was generally very low in children aged $0-9$ years, regardless of race/ethnic group. The highest reported prevalence was observed in American Indian children and adolescents: 0.021 and 1.45 per 1000 people at $0-9$ and 10-19 years of age, respectively (Table 1). In non-Hispanic black children and adolescents aged 10-19 years, the prevalence was slightly lower than in American Indian children and adolescents (1.06 per 1000 people). The SEARCH study ascertained incidence rates of clinically diagnosed type 2 diabetes from 2003 through to 2012 . Rates were lowest and more stable, or increased only slightly in most USA race/ethnic groups, but were highest and increased rapidly over the study period in non-Hispanic black and American Indian/Alaska Native youth (Fig. 3) [51]. The reported diabetes prevalence in Asian/Pacific Island and HispanicAmerican children and adolescents aged 10-19 years is 0.52 and 0.46 per 1000 people, respectively (Table 1) [52-54], while non-Hispanic white children and adolescents have a very low prevalence of type 2 diabetes at $10-19$ years of 0.18 per 1000 people. During 2011-2012, 5300 children and adolescents aged 10-19 years were diagnosed with type 2 diabetes and the incidence rates were higher among USA youth in minority groups (especially non-Hispanic black individuals and American Indians) compared with non-Hispanic white youth [55]. 
Table 1 Prevalence of diagnosed type 2 diabetes in youth in the USA by race/ethnicity

\begin{tabular}{llll}
\hline Race/ethnicity & \multicolumn{2}{l}{$\begin{array}{l}\text { Type 2 diabetes prevalence } \\
\text { (per 1000 people) }\end{array}$} & Reference \\
\cline { 2 - 3 } & $0-9$ years & $10-19$ years & \\
\hline Non-Hispanic white & 0.0046 & 0.18 & {$[55]$} \\
Non-Hispanic black & 0.0005 & 1.06 & {$[52]$} \\
Hispanic-American & 0.0003 & 0.46 & {$[53]$} \\
Asian and Pacific Islander & 0.014 & 0.52 & {$[54]$} \\
American Indian & 0.021 & 1.45 & {$[50]$} \\
\hline
\end{tabular}

In some racial/ethnic groups, in utero and infant conditions are risk factors for obesity or type 2 diabetes in later life. In studies in India, as described above, small size at birth and nutritional deficiencies (e.g. in vitamin $B_{12}$ ) [45] are associated with other diabetes risk factors. In Pima Indians in the USA, exposure to maternal diabetes in utero is a strong risk factor for obesity and type 2 diabetes in the offspring, especially in childhood and early adulthood $[56,57]$. Because type 2 diabetes often develops before or during childbearing years, the daughters of mothers who had diabetes during pregnancy then perpetuate the process during their own pregnancies, thus leading to a vicious cycle of diabetes in one generation begetting diabetes in the subsequent generation, as illustrated in Fig. 4 [48]. This cycle has resulted in increasing obesity and type 2 diabetes prevalence and incidence rates over a period of several decades; it is estimated that the type 2 diabetes risk attributable to exposure to diabetes in utero increased from $18.1 \%$ in $1967-76$ to $35.4 \%$ in 1987-1996 [49]. Increased type 2 diabetes incidence in children and young adults exposed to maternal type 2 diabetes in utero has also been observed in Hispanic-Americans and other populations [58]. The prevalence of pre-existing diabetes in pregnancy in the USA was estimated to vary almost threefold, from $0.60 \%$ in nonHispanic white individuals to $1.72 \%$ in American Indians/ Alaska Natives [59]. Being overweight and obese contribute to gestational diabetes mellitus (GDM), defined as diabetes or impaired glucose tolerance first recognised in pregnancy. In California (USA), the estimated prevalence of GDM in pregnancies during 2007-2009 ranged from 5.4\% in white women to $11.9 \%$ in Asian/Pacific Island women. The fraction of GDM attributed to being overweight or obese ranged from $41.2 \%$ in white women to $57.8 \%$ in American Indians [60].

We hypothesise that the effects of low birthweight, early nutritional deficiencies, and in utero exposure to maternal type 2 diabetes are not limited to any racial/ethnic group, but are magnified in certain groups with high risk of young-onset type 2 diabetes, especially American Indians. The vicious cycle of transgenerational inheritance of diabetes risk probably exists in all populations in which type 2 diabetes occurs before reproductive age, but it may be evident only in those racial/ ethnic groups in which type 2 diabetes frequently occurs at young ages. This likely explains the more rapid rise in incidence of type 2 diabetes from 2003-2012 in American Indians and non-Hispanic black individuals vs other racial/ethnic groups in the USA, in which rates were lower at the start of the study (Fig. 3) [51]. Similarly, the effects of early nutritional deficiencies and developmental delays are likely to have the greatest population-level impact and, thus, be most evident in racial/ethnic groups that have higher type 2 diabetes incidence rates at young ages.

\section{Prevalence and incidence of type 2 diabetes in adults}

Diabetes in adults: prevalence In the USA, an estimated $12.2 \%$ of adults (age $\geq 18$ years), or 30.2 million people, have diabetes; the prevalence of diagnosed and undiagnosed diabetes are $9.3 \%$ and $2.9 \%$, respectively [55]. The highest prevalence of diagnosed diabetes was observed among American Indians/Alaska Natives (Table 2). Non-Hispanic white individuals and Asian-Americans have similar prevalences of diabetes, whereas, in comparison, the non-Hispanic black population and Hispanic-Americans overall have higher prevalences (Table 2). Among Hispanic-American populations,
Fig. 3 Incidence of diagnosed type 2 diabetes in youth (aged 10 19 years) in the USA by race/ethnicity according to the SEARCH study. This figure was created using data in Table 2 of reference [51]. AI/AN, American Indian/Alaska Native; NHB, nonHispanic black; NHW, nonHispanic white. This figure is available as part of a downloadable slideset

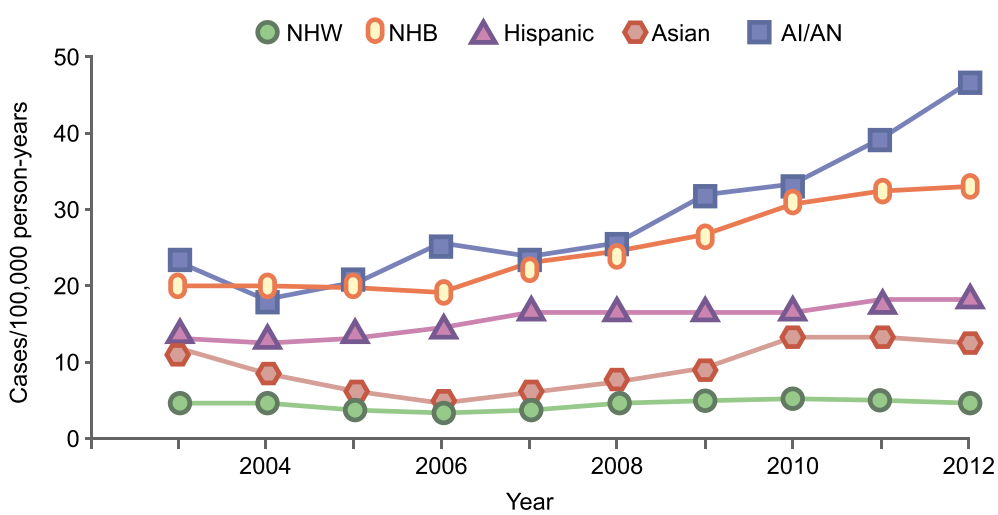




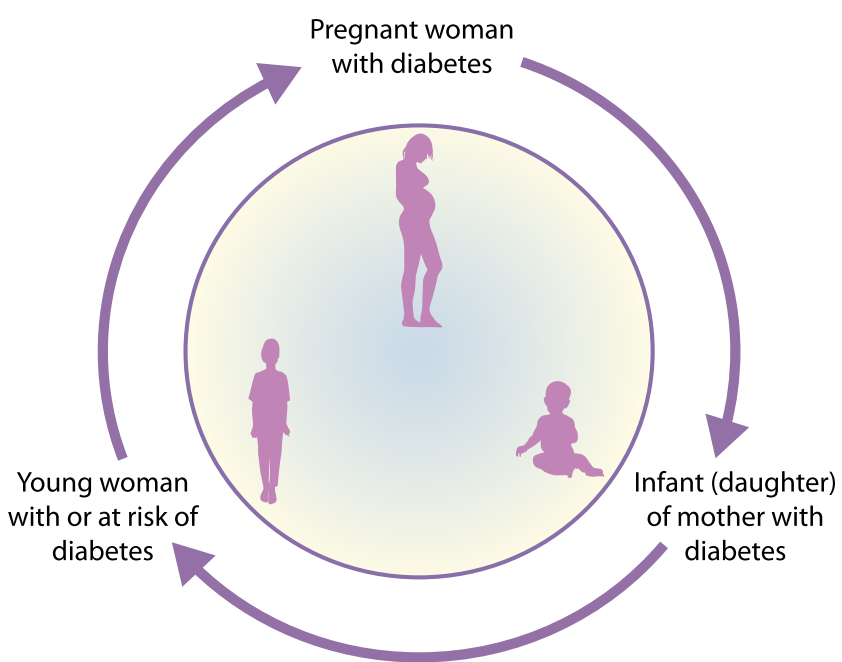

Fig. 4 Infants of mothers with diabetes, at least in high-risk populations such as American Indians, are at high risk of developing diabetes as children and young adults. By the time they become pregnant, these female offspring may already have diabetes and, thus, perpetuate this vicious cycle. Adapted from [48], with permission from John Wiley and Sons. This figure is available as part of a downloadable slideset

prevalence varies based on country of origin. MexicanAmericans had the highest prevalence of diabetes, followed by Puerto Ricans, Cubans and Central/South Americans. Diabetes prevalences among Asian-Americans also differ by countries of origin, being highest among Asian Indians and lowest among people from China [55]. The racial/ethnic differences in type 2 diabetes prevalence in the USA are likely to be confounded and modified by SES, body size and diet. In the Boston Area Community Health Survey, SES was associated with race/ethnicity, but SES was more strongly related to type 2 diabetes than was race/ethnicity; when adjusted for SES, black and Hispanic race/ethnicity was no longer significantly associated with the prevalence of type 2 diabetes [61]. In the Multi-Ethnic Study of Atherosclerosis in the USA, the effect of BMI in predicting incident diabetes differed significantly by race/ethnicity, being greatest in Chinese-Americans and lowest in black individuals [62]. In contrast, in the same study, there was no significant interaction of race/ethnicity with dietary patterns in predicting diabetes [63].

Table 2 Age-adjusted prevalence of diagnosed type 2 diabetes in the USA by race/ethnicity in adults $\geq 18$ years of age [55]

\begin{tabular}{ll}
\hline Racial/ethnic group & Age-adjusted prevalence (\%) \\
\hline Non-Hispanic white & 7.4 \\
Asian-American & 8.0 \\
Hispanic-American & 12.1 \\
Non-Hispanic black & 12.7 \\
American Indian/Alaska Native & 15.1 \\
\hline
\end{tabular}

Table 3 summarises the age-adjusted prevalence of diabetes in various regions of the world [64]. In 2017, 365 million people worldwide had a diagnosis of diabetes. The Western Pacific region had the highest number of individuals (159 million) diagnosed with diabetes, with an age-adjusted prevalence of $8.6 \%$. The North America/Caribbean region had the highest prevalence (11.0\%) and Africa had the lowest prevalence (4.4\%); however, the Africa region has the highest proportion of undiagnosed diabetes $(\geq 70 \%)$ [64].

The Indian subcontinent is an epicentre of diabetes burden $[10,65]$. India is second only to China in the number of people with diabetes. There is great population diversity within India, and data are available by state, urban/rural residence, and socioeconomic position, but not by 'race/ethnicity' as defined in the USA. The South Asian region is expected to have the world's largest number of individuals living with diabetes by 2030 [30]. The prevalence varies by country within the South Asian region, with India having the largest burden.

There have been a large number of epidemiological reports of diabetes prevalence in India over the last 30 years, most from South India. The recently reported Indian Council of Medical Research-India Diabetes (ICMR-INDIAB) study was the largest population-based study, carried out over 15 states, representing half of India's vast population [24]. The overall prevalence of diabetes was estimated at $7.3 \%$. Highlighting the heterogeneity of the population of India, there was wide variation in the prevalence of type 2 diabetes in different states, which paralleled the per capita gross domestic product (GDP). Prevalence was higher in urban vs rural areas. While diabetes was higher among the affluent in rural areas, in urban areas it was more common in those with lower socioeconomic scores [24].

The rise in diabetes prevalence in India parallels a worldwide rise from $4.7 \%$ in 1980 to $8.5 \%$ in 2014 [66]. In a recent comparison between two surveys in the southern Indian state of Tamil Nadu, using similar methods carried out 10 years apart (2006 and 2016) [67], diabetes prevalence increased significantly in a city (from $18.6 \%$ to $21.9 \%$ ), a town ( $16.4 \%$ to $20.3 \%$ ), and in peri-urban villages $(9.2 \%$ to

Table 3 Age-adjusted prevalence of diagnosed type 2 diabetes in adults aged 20-79 years, in different regions of the world in 2017 [64]

\begin{tabular}{lc}
\hline Region & Age-adjusted prevalence (\%) \\
\hline Africa & 4.4 \\
Europe & 6.8 \\
Middle East and North Africa & 10.8 \\
North America and the Caribbean & 11.0 \\
South and Central America & 7.6 \\
South East Asia & 10.1 \\
Western Pacific & 8.6 \\
\hline
\end{tabular}


13.4\%). At both time points, there was an urban-village gradient, with prevalences being highest in the city (defined as having a population $\geq 4$ million) and lowest in villages, where occupations were primarily agricultural. In addition to age and family history of diabetes, central obesity was associated with increases in prevalence.

Diabetes prevalence and migration Studies that compare prevalence of diabetes in migrants to that of individuals in their country of origin can yield information about the importance of environmental factors, under the assumption that the two groups are genetically similar. In general, migrants to more urbanised, industrialised countries have a higher prevalence of diabetes than individuals in their countries of origin [68]. For example, populations of African origin living in the USA or the UK have higher prevalence of diabetes than those living in African countries, whereas prevalence is intermediate in individuals of African ancestry living in Jamaica [69, 70]. Similarly, migrants from the Polynesian atoll of Tokelau living in New Zealand had a higher risk of diabetes than those who remained in Tokelau [71], and second-generation Indian immigrants in Singapore had a higher prevalence of diabetes than first-generation migrants [72]. On the other hand, in a comparison between Indians living in the USA and those living in urban India (Chennai), those in India had higher prevalence of diabetes than the Indian-Americans [73]. In addition, the prevalence of diabetes in urban Ghana was much higher than in rural Ghana and comparable with that of African-origin populations in urban Europe [74]. Moreover, among Peruvians who migrated from rural to urban areas, the risk of developing diabetes was much higher than among those who remained in the rural regions [75]. These studies implicate environmental factors associated with urbanisation as contributing to the high risk of diabetes in migrant populations.

Diabetes in adults: incidence In adults from the USA, aged $\geq 18$ years, there were approximately 1.5 million new cases of diabetes according to the National Health Interview Survey (NHIS) in 2015 [55]. The annual age-adjusted incidence of diagnosed diabetes was higher in non-Hispanic black individuals ( 9.0 per 1000 people) and individuals of Hispanic origin (8.4 per 1000 people) compared with non-Hispanic white individuals (5.7 per 1000 people) and Asians (6.0 per 1000 person-years). Overall diabetes incidence in the NHIS increased rapidly during 1990-2008, followed by a levelling off and then a decrease from 2008-2012; however, this primarily occurred in non-Hispanic white individuals, while the incidence continued to rise in non-Hispanic black people and Hispanic individuals during this same time period [1]. We were unable to identify regional data on worldwide diabetes incidence.

\section{Other factors that may contribute to racial/ethnic differences in type 2 diabetes}

Genetic variation, as discussed above, is an obvious candidate that may explain racial/ethnic variation in type 2 diabetes. A limitation is that most research on genetics of diabetes has been conducted in the USA, Europe or eastern Asia, but most areas of the world have not been well represented. Therefore, genetic variants that may have large effects but are found only in some populations may not have been discovered. Factors in the external environment must also be considered. Arsenic is a naturally occurring toxin in many parts of the world. Exposure to it has been associated with the prevalence of type 2 diabetes in several different countries, including Bangladesh [76, 77], Mexico [78] and the USA [79, 80]. Environmental exposure to persistent organic pollutants and several heavy metals has also been associated with diabetes [81-83]. There is also evidence that infection with the hepatitis $\mathrm{C}$ virus, and perhaps other viruses, may increase diabetes risk [84]. Such environmental factors vary geographically, so they may increase diabetes incidence in areas that are inhabited predominantly by certain racial/ethnic groups. Thus, some racial/ethnic differences in disease susceptibility could be caused by environmental exposures that differ by race/ethnicity. If the environmental exposures are not known or considered, these differences could be erroneously attributed to genetics or other factors.

\section{Race/ethnicity in preventing type 2 diabetes}

Despite the large differences in diabetes incidence rates among different populations around the world, the progression from high-risk states (such as being overweight or obese with impaired glucose regulation, or so-called 'prediabetes') to overt diabetes has been shown to occur at similar rates and responded similarly to preventive interventions among different racial/ethnic groups in the USA Diabetes Prevention Program [85]. Most behavioural or medical interventions for diabetes prevention have worked in racially/ethnically diverse populations around the world [86]. The achieved reductions in rates of type 2 diabetes incidence differed among clinical trials conducted in different countries, but the differences may be due to differences in the types or intensities of interventions among the studies rather than race/ethnicity. To our knowledge, only the USA Diabetes Prevention Program compared effects of the same interventions given to different racial/ ethnic groups; the effects of the metformin and lifestyle interventions on reducing progression to type 2 diabetes did not differ significantly by race/ethnicity [85]. Thus, despite the racial/ethnic differences in diabetes prevalence, current methods for diabetes prevention are the same across racial and ethnic categories. 


\section{Conclusions}

This review summarises differences in the frequencies of type 2 diabetes according to race, ethnicity, socioeconomic position, area of residence and environmental toxins. The causes of these differences are not well understood. Specifically, the relative contributions of genetic and environmental factors to racial/ethnic differences are largely unknown. With a few exceptions in isolated populations, there is little evidence that differences in frequencies of known type 2 diabetes susceptibility genetic alleles account for racial/ethnic differences in type 2 diabetes, although the search for genetic susceptibility has not been uniform among the world's racial/ethnic groups. In the USA, race/ethnicity is associated with many other risk factors for type 2 diabetes, including being overweight/obese, diet and SES. Some studies suggest that some of these factors may account for the race/ethnic differences in prevalence of type 2 diabetes, although there is inadequate research in this area. Better understanding of these factors should lead to more effective prevention and treatment. This has not yet been achieved to a great extent but should be a goal for the future.

Acknowledgements CY thanks R. Wagh (Diabetes Unit, KEM Hospital and Research Center, Pune, Maharashtra, India) for assistance.

Funding In some of the studies mentioned in the review, CY has been supported by grants from: The Wellcome Trust, UK; the Medical Research Council of the UK; the Department of Biotechnology of the Government of India; and the Indian Council of Medical Research. RLH and WCK are supported by the Intramural Research Program of the National Institute of Diabetes and Digestive and Kidney Diseases, USA.

Duality of interest The authors declare that there is no duality of interest associated with this manuscript.

Contribution All authors were responsible for drafting the article and revising it critically for important intellectual content. All authors approved the version to be published.

\section{References}

1. Cowie CC, Casagrande SS, Geiss LS (2018) Prevalence and incidence of type 2 diabetes and prediabetes. In: Cowie CC, Casagrande SS, Menke A et al (eds) Diabetes in America, 3rd edn. National Institutes of Health, Bethesda, MD, pp 3-1-3-32

2. Williams DR (1997) Race and health: basic questions, emerging directions. Ann Epidemiol 7(5):322-333. https://doi.org/10.1016/ S1047-2797(97)00051-3

3. Karter AJ (2003) Commentary: race, genetics, and disease - in search of a middle ground. Int J Epidemiol 32(1):26-28. https:// doi.org/10.1093/ije/dyg033

4. Karter AJ (2003) Race and ethnicity: vital constructs for diabetes research. Diabetes Care 26(7):2189-2193. https://doi.org/10.2337/ diacare.26.7.2189

5. Golden SH, Brown A, Cauley JA et al (2012) Health disparities in endocrine disorders: biological, clinical, and nonclinical factorsan Endocrine Society scientific statement. J Clin Endocrinol Metab 97(9):E1579-E1639. https://doi.org/10.1210/jc.2012-2043
6. Spanakis EK, Golden SH (2013) Race/ethnic difference in diabetes and diabetic complications. Curr Diab Rep 13(6):814-823. https:// doi.org/10.1007/s11892-013-0421-9

7. Gardner LI Jr, Stern MP, Haffner SM et al (1984) Prevalence of diabetes in Mexican Americans. Relationship to percent of gene pool derived from native American sources. Diabetes 33(1):8692. https://doi.org/10.2337/diab.33.1.86

8. Knowler WC, Williams RC, Pettitt DJ, Steinberg AG (1988) $\mathrm{Gm}^{3 ; 5 \text {, }}$ 13,14 and type 2 diabetes mellitus: an association in American Indians with genetic admixture. Am J Hum Genet 43(4):520-526

9. Williams RC, Long JC, Hanson RL, Sievers ML, Knowler WC (2000) Individual estimates of European genetic admixture associated with lower body-mass index, plasma glucose, and prevalence of type 2 diabetes in Pima Indians. Am J Hum Genet 66(2):527538. https://doi.org/10.1086/302773

10. Hanis CL, Chakraborty R, Ferrell RE, Schull WJ (1986) Individual admixture estimates: disease associations and individual risk of diabetes and gallbladder disease among Mexican-Americans in Starr County, Texas. Am J Phys Anthropol 70(4):433-441. https://doi.org/10.1002/ajpa.1330700404

11. Chakraborty R, Ferrell RE, Stern MP, Haffner SM, Hazuda HP, Rosenthal M (1986) Relationship of prevalence of non-insulindependent diabetes mellitus to Amerindian admixture in the Mexican Americans of San Antonio, Texas. Genet Epidemiol 3(6):435-454. https://doi.org/10.1002/gepi.1370030608

12. Florez JC, Price AL, Campbell D et al (2009) Strong association of socioeconomic status with genetic ancestry in Latinos: implications for admixture studies of type 2 diabetes. Diabetologia 52(8):1528 1536. https://doi.org/10.1007/s00125-009-1412-x

13. Parra EJ, Hoggart CJ, Bonilla C et al (2004) Relation of type 2 diabetes to individual admixture and candidate gene polymorphisms in the Hispanic American population of San Luis Valley, Colorado. J Med Genet 41(11):e116. https://doi.org/10.1136/jmg. 2004.018887

14. Martinez-Marignac VL, Valladares A, Cameron E et al (2007) Admixture in Mexico City: implications for admixture mapping of type 2 diabetes genetic risk factors. Hum Genet 120(6):807819. https://doi.org/10.1007/s00439-006-0273-3

15. Campbell DD, Parra MV, Duque C et al (2012) Amerind ancestry, socioeconomic status and the genetics of type 2 diabetes in a Colombian population. PLoS One 7(4):e33570. https://doi.org/10. 1371/journal.pone.0033570

16. Cheng CY, Reich D, Haiman CA et al (2012) African ancestry and its correlation to type 2 diabetes in African Americans: a genetic admixture analysis in three U.S. population cohorts. PLoS One 7(3):e32840. https://doi.org/10.1371/journal.pone.0032840

17. Mahajan A, Taliun D, Thurner M et al (2018) Fine-mapping type 2 diabetes loci to single-variant resolution using high-density imputation and islet-specific epigenome maps. Nat Genet 50(11):15051513. https://doi.org/10.1038/s41588-018-0241-6

18. Hegele RA, Zinman B, Hanley AJG, Harris SB, Barrett PH, Cao HN (2003) Genes, environment and Oji-Cree type 2 diabetes. Clin Biochem 36(3):163-170. https://doi.org/10.1016/S0009-9120(03) 00004-3

19. Moltke I, Grarup N, Jorgensen ME et al (2014) A common Greenlandic TBC1D4 variant confers muscle insulin resistance and type 2 diabetes. Nature 512(7513):190-193. https://doi.org/ 10.1038 /nature 13425

20. Klimentidis YC, Abrams M, Wang JL, Fernandez JR, Allison DB (2011) Natural selection at genomic regions associated with obesity and type-2 diabetes: East Asians and sub-Saharan Africans exhibit high levels of differentiation at type-2 diabetes regions. Hum Genet 129(4):407-418. https://doi.org/10.1007/s00439-010-0935-z

21. Chen R, Corona E, Sikora M et al (2012) Type 2 diabetes risk alleles demonstrate extreme directional differentiation among 
human populations, compared to other diseases. PLoS Genet 8(4): e1002621. https://doi.org/10.1371/journal.pgen.1002621

22. Corona E, Chen R, Sikora M et al (2013) Analysis of the genetic basis of disease in the context of worldwide human relationships and migration. PLoS Genet 9(5):e1003447. https://doi.org/10.1371/ journal.pgen. 1003447

23. Hanson RL, Rong R, Kobes S et al (2015) Role of established type 2 diabetes-susceptibility genetic variants in a high prevalence American Indian population. Diabetes 64(7):2646-2657. https:// doi.org/10.2337/db14-1715

24. Anjana RM, Deepa M, Pradeepa R et al (2017) Prevalence of diabetes and prediabetes in 15 states of India: results from the ICMR-INDIAB population-based cross-sectional study. Lancet Diabetes Endocrinol 5(8):585-596. https://doi.org/10.1016/S2213-8587(17)30174-2

25. Hales CN, Barker DJ (1992) Type 2 (non-insulin-dependent) diabetes mellitus: the thrifty phenotype hypothesis. Diabetologia 35(7):595-601. https://doi.org/10.1007/BF00400248

26. Chandalia HBSG, Das AK, Madhu SV, Mohan V, Rao PV (2014) RSSDI textbook of diabetes mellitus, 3rd edn. Jaypee Brothers Medical Publishers, New Delhi, India. https://doi.org/10.5005/jp/ books/12626

27. Yajnik CS (2001) The insulin resistance epidemic in India: fetal origins, later lifestyle, or both? Nutr Rev 59(1 Pt 1):1-9. https:// doi.org/10.1111/j.1753-4887.2001.tb01898.x

28. Deurenberg P, Yap M, van Staveren WA (1998) Body mass index and percent body fat: a meta analysis among different ethnic groups. Int J Obes Relat Metab Disord 22(12):1164-1171. https:// doi.org/10.1038/sj.ijo.0800741

29. Yajnik CS, Yudkin JS (2004) The Y-Y paradox. Lancet 363(9403): 163. https://doi.org/10.1016/S0140-6736(03)15269-5

30. Gujral UP, Pradeepa R, Weber MB, Narayan KM, Mohan V (2013) Type 2 diabetes in south Asians: similarities and differences with white Caucasian and other populations. Ann N Y Acad Sci 1281(1): 51-63. https://doi.org/10.1111/j.1749-6632.2012.06838.x

31. Yajnik CS, Fall CH, Coyaji KJ et al (2003) Neonatal anthropometry: the thin-fat Indian baby. The Pune maternal nutrition study. Int J Obes Relat Metab Disord 27(2):173-180. https://doi.org/10.1038/ sj.ijo.802219

32. Hales CN, Barker DJ, Clark PM et al (1991) Fetal and infant growth and impaired glucose tolerance at age 64. BMJ 303(6809):10191022. https://doi.org/10.1136/bmj.303.6809.1019

33. Modi N, Thomas EL, Uthaya SN, Umranikar S, Bell JD, Yajnik C (2009) Whole body magnetic resonance imaging of healthy newborn infants demonstrates increased central adiposity in Asian Indians. Pediatr Res 65(5):584-587. https://doi.org/10.1203/01. pdr.0000350364.10602.33

34. Yajnik CS, Lubree HG, Rege SS et al (2002) Adiposity and hyperinsulinemia in Indians are present at birth. J Clin Endocrinol Metab 87(12):5575-5580. https://doi.org/10.1210/jc.2002-020434

35. Gluckman PD, Hanson MA, Cooper C, Thornburg KL (2008) Effect of in utero and early-life conditions on adult health and disease. N Engl J Med 359(1):61-73. https://doi.org/10.1056/ NEJMra0708473

36. Chandak GR, Silver MJ, Saffari A et al (2017) Protocol for the EMPHASIS study; epigenetic mechanisms linking maternal preconceptional nutrition and children's health in India and subSaharan Africa. BMC Nutr 3(1):81. https://doi.org/10.1186/ s40795-017-0200-0

37. Yajnik CS, Fall CH, Vaidya U et al (1995) Fetal growth and glucose and insulin metabolism in four-year-old Indian children. Diabet Med 12(4):330-336. https://doi.org/10.1111/j.1464-5491.1995. tb00487.x

38. Bavdekar A, Yajnik CS, Fall CH et al (1999) Insulin resistance syndrome in 8-year-old Indian children: small at birth, big at 8 years, or both? Diabetes 48(12):2422-2429. https://doi.org/10. 2337/diabetes.48.12.2422
39. Bhargava SK, Sachdev HS, Fall CH et al (2004) Relation of serial changes in childhood body-mass index to impaired glucose tolerance in young adulthood. N Engl J Med 350(9):865-875. https:// doi.org/10.1056/NEJMoa035698

40. Yajnik CS (2009) Nutrient-mediated teratogenesis and fuelmediated teratogenesis: two pathways of intrauterine programming of diabetes. Int J Gynaecol Obstet 104(Suppl 1):S27-S31. https:// doi.org/10.1016/j.ijgo.2008.11.034

41. Ebrahim S, Kinra S, Bowen L et al (2010) The effect of rural-tourban migration on obesity and diabetes in India: a cross-sectional study. PLoS Med 7(4):e1000268. https://doi.org/10.1371/journal. pmed. 1000268

42. Wells JC, Pomeroy E, Walimbe SR, Popkin BM, Yajnik CS (2016) The elevated susceptibility to diabetes in India: an evolutionary perspective. Front Public Health 4:145. https://doi.org/10.3389/ fpubh.2016.00145

43. Yajnik C, Joglekar C, Lubree H et al (2008) Adiposity, inflammation and hyperglycaemia in rural and urban Indian men: Coronary Risk of Insulin Sensitivity in Indian Subjects (CRISIS) Study. Diabetologia 51(1):39-46. https://doi.org/10.1007/s00125-007-0847-1

44. Petersen KF, Dufour S, Feng J et al (2006) Increased prevalence of insulin resistance and nonalcoholic fatty liver disease in AsianIndian men. Proc Natl Acad Sci U S A 103(48):18273-18277. https://doi.org/10.1073/pnas.0608537103

45. Yajnik CS, Deshpande SS, Jackson AA et al (2008) Vitamin $B_{12}$ and folate concentrations during pregnancy and insulin resistance in the offspring: the Pune maternal nutrition study. Diabetologia 51(1): 29-38. https://doi.org/10.1007/s00125-007-0793-y

46. Burden M, Samanta A, Spalding D, Burden A (1994) A comparison of the glycaemic and insulinaemic effects of an Asian and a European meal. Practical Diabetes International 11(5):208-211. https://doi.org/10.1002/pdi.1960110508

47. Fischbacher C, Hunt S, Alexander L (2004) How physically active are south Asians in the United Kingdom? A literature review. J Public Health 26(3):250-258. https://doi.org/10.1093/pubmed/ fdh 158

48. Knowler WC, Pettitt DJ, Saad MF, Bennett PH (1990) Diabetes mellitus in the Pima Indians: incidence, risk factors and pathogenesis. Diabetes Metab Rev 6(1):1-27. https://doi.org/10.1002/dmr. 5610060101

49. Dabelea D, Hanson RL, Bennett PH, Roumain J, Knowler WC, Pettitt DJ (1998) Increasing prevalence of type II diabetes in American Indian children. Diabetologia 41(8):904-910. https:// doi.org/10.1007/s001250051006

50. Dabelea D, DeGroat J, Sorrelman C et al (2009) Diabetes in Navajo youth. Prevalence, incidence, and clinical characteristics: the SEARCH for diabetes in youth study. Diabetes Care 32(Suppl 2): S141-S147. https://doi.org/10.2337/dc09-S206

51. Mayer-Davis EJ, Lawrence JM, Dabelea D et al (2017) Incidence trends of type 1 and type 2 diabetes among youths, 2002-2012. N Engl J Med 376(15):1419-1429. https://doi.org/10.1056/ NEJMoa1610187

52. Mayer-Davis EJ, Beyer J, Bell RA et al (2009) Diabetes in African American youth. Prevalence, incidence, and clinical characteristics: the SEARCH for diabetes in youth study. Diabetes Care 32(Suppl 2):S112-S122. https://doi.org/10.2337/dc09-S203

53. Lawrence JM, Mayer-Davis EJ, Reynolds K et al (2009) Diabetes in Hispanic American youth. Prevalence, incidence, demographics, and clinical characteristics: the SEARCH for diabetes in youth study. Diabetes Care 32(Suppl 2):S123-S132. https://doi.org/10. 2337/dc09-S204

54. Liu LL, Yi JP, Beyer J et al (2009) Type 1 and type 2 diabetes in Asian and Pacific islander U.S. youth: the SEARCH for diabetes in youth study. Diabetes Care 32(Suppl 2):S133-S140. https://doi.org/ $10.2337 / \mathrm{dc} 09-\mathrm{S} 205$ 
55. Centers for Disease Control and Prevention (2017) National Diabetes Statistics Report, 2017. Available from: www.cdc.gov/ diabetes/pdfs/data/statistics/national-diabetes-statistics-report.pdf. Accessed 8 April 2019

56. Pettitt DJ, Baird HR, Aleck KA, Bennett PH, Knowler WC (1983) Excessive obesity in offspring of Pima Indian women with diabetes during pregnancy. N Engl J Med 308(5):242-245. https://doi.org/ 10.1056/Nejm198302033080502

57. Pettitt DJ, Aleck KA, Baird HR, Carraher MJ, Bennett PH, Knowler WC (1988) Congenital susceptibility to NIDDM. Role of intrauterine environment. Diabetes 37(5):622-628. https://doi. org/10.2337/diab.37.5.622

58. Dabelea D, Mayer-Davis EJ, Lamichhane AP et al (2008) Association of intrauterine exposure to maternal diabetes and obesity with type 2 diabetes in youth: the SEARCH case-control study. Diabetes Care 31(7):1422-1426. https://doi.org/10.2337/dc072417

59. Kitzmiller JL, Ferrara A, Peng T, Cissel MA, Kim C (2018) Preexisting diabetes and pregnancy. In: Cowie CC, Casagrande SS, Menke A et al (eds) Diabetes in America, 3rd edn. National Institutes of Health, Bethesda, MD, pp 5-1-5-106

60. Kim SY, Saraiva C, Curtis M, Wilson HG, Troyan J, Sharma AJ (2013) Fraction of gestational diabetes mellitus attributable to overweight and obesity by race/ethnicity, California, 2007-2009. Am J Public Health 103(10):e65-e72. https://doi.org/10.2105/AJPH. 2013.301469

61. Link CL, McKinlay JB (2009) Disparities in the prevalence of diabetes: is it race/ethnicity or socioeconomic status? Results from the Boston Area Community Health (BACH) survey. Ethn Dis 19(3):288-292

62. Lutsey PL, Pereira MA, Bertoni AG, Kandula NR, Jacobs DR Jr (2010) Interactions between race/ethnicity and anthropometry in risk of incident diabetes: the multi-ethnic study of atherosclerosis. Am J Epidemiol 172(2):197-204. https://doi.org/10.1093/aje/ kwq100

63. Nettleton JA, Steffen LM, Ni H, Liu K, Jacobs DR Jr (2008) Dietary patterns and risk of incident type 2 diabetes in the MultiEthnic Study of Atherosclerosis (MESA). Diabetes Care 31(9): 1777-1782. https://doi.org/10.2337/dc08-0760

64. International Diabetes Federation (2017) IDF Diabetes atlas, 8th edn. Available from: https://diabetesatlas.org/resources/2017-atlas. html. Accessed 8 April 2019

65. Ramachandran A, Ma RC, Snehalatha C (2010) Diabetes in Asia. Lancet 375(9712):408-418. https://doi.org/10.1016/S01406736(09)60937-5

66. The Emerging Risk Factors Collaboration (2010) Diabetes mellitus, fasting blood glucose concentration, and risk of vascular disease: a collaborative meta-analysis of 102 prospective studies. Lancet 375(9733):2215-2222. https://doi.org/10.1016/S0140-6736(10) 60484-9

67. Nanditha A, Snehalatha C, Satheesh K et al (2019) Secular TRends in DiabEtes in India (STRiDE-I): change in prevalence in 10 years among urban and rural populations in Tamil Nadu. Diabetes Care 42(3):476-485. https://doi.org/10.2337/dc18-1559

68. Misra A, Ganda OP (2007) Migration and its impact on adiposity and type 2 diabetes. Nutrition 23(9):696-708. https://doi.org/10. 1016/j.nut.2007.06.008

69. Rotimi CN, Cooper RS, Okosun IS et al (1999) Prevalence of diabetes and impaired glucose tolerance in Nigerians, Jamaicans and US blacks. Ethn Dis 9(2):190-200

70. Mbanya JC, Cruickshank JK, Forrester T et al (1999) Standardized comparison of glucose intolerance in west African-origin populations of rural and urban Cameroon, Jamaica, and Caribbean migrants to Britain. Diabetes Care 22(3):434-440. https://doi.org/10. 2337/diacare.22.3.434
71. Ostbye T, Welby TJ, Prior IA, Salmond CE, Stokes YM (1989) Type 2 (non-insulin-dependent) diabetes mellitus, migration and westernisation: the Tokelau Island migrant study. Diabetologia 32(8):585-590

72. Zheng Y, Lamoureux EL, Ikram MK et al (2012) Impact of migration and acculturation on prevalence of type 2 diabetes and related eye complications in Indians living in a newly urbanised society. PLoS One 7(4):e34829. https://doi.org/10.1371/journal.pone. 0034829

73. Gujral UP, Narayan KM, Pradeepa RG et al (2015) Comparing type 2 diabetes, prediabetes, and their associated risk factors in Asian Indians in India and in the U.S.: the CARRS and MASALA studies. Diabetes Care 38(7):1312-1318. https://doi.org/10.2337/dc15-0032

74. Agyemang C, Meeks K, Beune E et al (2016) Obesity and type 2 diabetes in sub-Saharan Africans - is the burden in today's Africa similar to African migrants in Europe? The RODAM study. BMC Med 14(1):166. https://doi.org/10.1186/s12916-016-0709-0

75. Ruiz-Alejos A, Carrillo-Larco RM, Miranda JJ et al (2018) Addressing the impact of urban exposure on the incidence of type 2 diabetes mellitus: the PERU MIGRANT study. Sci Rep 8(1): 5512. https://doi.org/10.1038/s41598-018-23812-6

76. Rahman M, Tondel M, Ahmad SA, Axelson O (1998) Diabetes mellitus associated with arsenic exposure in Bangladesh. Am J Epidemiol 148(2):198-203. https://doi.org/10.1093/oxfordjournals. aje.a009624

77. Pan WC, Seow WJ, Kile ML et al (2013) Association of low to moderate levels of arsenic exposure with risk of type 2 diabetes in Bangladesh. Am J Epidemiol 178(10):1563-1570. https://doi.org/ 10.1093/aje/kwt195

78. Coronado-Gonzalez JA, Del Razo LM, Garcia-Vargas G, Sanmiguel-Salazar F, la Pena JE (2007) Inorganic arsenic exposure and type 2 diabetes mellitus in Mexico. Environ Res 104(3):383389. https://doi.org/10.1016/j.envres.2007.03.004

79. Navas-Acien A, Silbergeld EK, Pastor-Barriuso R, Guallar E (2008) Arsenic exposure and prevalence of type 2 diabetes in US adults. JAMA 300(7):814-822. https://doi.org/10.1001/jama.300.7.814

80. Kim NH, Mason CC, Nelson RG et al (2013) Arsenic exposure and incidence of type 2 diabetes in southwestern American Indians. Am J Epidemiol 177(9):962-969. https://doi.org/10.1093/aje/kws329

81. Lee DH, Jacobs DR (2006) A strong dose-response relation between serum concentrations of persistent organic pollutants and diabetes: results from the National Health and Nutrition Examination Survey 1999-2002. Response to Porta. Diabetes Care 29(11):2568. https://doi.org/10.2337/dc06-1720

82. Grice BA, Nelson RG, Williams DE et al (2017) Associations between persistent organic pollutants, type 2 diabetes, diabetic nephropathy and mortality. Occup Environ Med 74(7):521-527. https://doi.org/10.1136/oemed-2016-103948

83. Menke A, Guallar E, Cowie CC (2016) Metals in urine and diabetes in US adults. Diabetes 65(1):164-171. https://doi.org/10.2337/ db15-0316

84. Ruhl CE, Menke A, Cowie CC, Everhart JE (2014) Relationship of hepatitis $\mathrm{C}$ virus infection with diabetes in the US population. Hepatology 60(4):1139-1149. https://doi.org/10.1002/hep.27047

85. Knowler WC, Barrett-Connor E, Fowler SE et al (2002) Reduction in the incidence of type 2 diabetes with lifestyle intervention or metformin. N Engl J Med 346(6):393-403. https://doi.org/10. 1056/NEJMoa012512

86. Knowler WC, Crandall JP, Chiasson J-L, Nathan DM (2018) Prevention of type 2 diabetes. In: Cowie CC, Casagrande SS, Menke A et al (eds) Diabetes in America, 3rd edn. National Institutes of Health, Bethesda, MD, pp 38-1-38-21

Publisher's note Springer Nature remains neutral with regard to jurisdictional claims in published maps and institutional affiliations. 